\title{
Reliability and Validity of the Korean Version of the Parental Stress Scale for Children With Attention-Deficit/Hyperactivity Disorder
}

\author{
Seo Young Park', Jung Ho Kim², Mi Young Jeong ${ }^{3}$, Yun Sung Lee ${ }^{4}$, Jeong Eun Shin ${ }^{4}$, and Yeon Jung Lee ${ }^{5 凶}$ \\ ${ }^{1}$ Sejong-si Community Mental Health Welfare Center, Sejong, Republic of Korea \\ ${ }^{2}$ Department of Nursing, Masan University, Changwon, Republic of Korea \\ ${ }^{3}$ Department of Psychiatry, Samsung Medical Center, Sungkyunkwan University School of Medicine, Seoul, Republic of Korea \\ ${ }^{4}$ Department of Medical Sciences, Graduate School of Soonchunhyang University, Asan, Republic of Korea \\ ${ }^{5}$ Department of Psychiatry, Soonchunhyang University Seoul Hospital, College of Medicine, Soonchunhyang University, Seoul, Republic of Korea
}

\begin{abstract}
Objective This study standardizes the Parental Stress Scale (PSS) for Republic of Korean parents of children with attention-deficit/hyperactivity disorder (ADHD) and verifies its reliability and validity.

Methods Data from 160 parents of children with ADHD who completed the following self-reported questionnaires were analyzed: the Korean ADHD Rating Scales, the Patient Health Questionnaire-9, the State-Trait Anxiety Inventory, the PSS, and the Global Assessment of Recent Stress Scale. All scale items were measured for reliability and validity, and the appropriate factors for measuring stress in Korean parents with ADHD children were extracted.

Results Exploratory and confirmatory factor analyses derived two sub-factors and 11 items. Goodness of fit was confirmed, and the scale was deemed suitable for explaining stress in parents of children with ADHD.

Conclusion In this study, the validity and reliability of the K-PSS-ADHD were investigated. We expect that the K-PSS-ADHD will be used as a basis for future studies on stress in parents of children with ADHD.
\end{abstract}

Psychiatry Investig 2021;18(12):1188-1197

Keywords Attention-deficit/hyperactivity disorder; Parental stress scale; Reliability; Validity.

\section{INTRODUCTION}

Attention-deficit/hyperactivity disorder (ADHD) is characterized by inattention, hyperactivity, and impulsivity. ADHD chronically affects family and school environments and society. ${ }^{1}$ As children age, they experience impairment in social interaction due to ADHD symptoms such as impulsivity and decreased attention. Also, these children receive negative feedback from others, which causes a general decrease in social function. ${ }^{2}$ Additionally, $50 \%$ of individuals diagnosed with ADHD in childhood continue to show symptoms in adulthood. ${ }^{1}$ They have difficulty efficiently managing time and systematically

Received: April 5, 2021 Revised: June 10, 2021

Accepted: August 8, 2021

$\triangle$ Correspondence: Yeon Jung Lee, MD, PhD

Department of Psychiatry, Soonchunhyang University Seoul Hospital, College of Medicine, Soonchunhyang University, 59 Daesagwan-ro, Yongsan-gu, Seoul 04401, Republic of Korea

Tel: +82-2-709-9081, Fax: +82-2-792-9938, E-mail: leeyj1203@schmc.ac.kr

(a) This is an Open Access article distributed under the terms of the Creative Commons Attribution Non-Commercial License (https://creativecommons.org/licenses/by$\mathrm{nc} / 4.0$ ) which permits unrestricted non-commercial use, distribution, and reproduction in any medium, provided the original work is properly cited. performing tasks. They may also require supervision to complete a given task, thereby affecting the lives of their family and society. ${ }^{3}$

Children with ADHD, who are difficult to nurture from childhood, are sensitive and often display unpredictable, temperamental characteristics. ${ }^{4}$ These children may also have irregular sleeping and other habits. Moreover, children with ADHD may be difficult to control, as they are overactive and impulsive. ${ }^{5}$ They are less compliant with parental demands and more hostile and negative toward their parents. These behaviors lead to an increased need for attention compared with typically developmental children. ${ }^{6}$ Therefore, parents of children with ADHD experience increased stress, and severe ADHD symptoms cause even greater parental stress. ${ }^{7}$ As parental stress increases, negative emotions increase as well, and parental satisfaction decreases. ${ }^{8}$ Thus, parents of children with ADHD experience more stress, frustration, and depression than parents of children without ADHD. ${ }^{9}$

While ADHD symptoms in children can affect parental stress, parental stress can also aggravate $\mathrm{ADHD}$ symptoms. In a pre- 
vious study, mothers of children with ADHD presented negative parenting behaviors, such as physical punishment, rejection of children, and indifference. ${ }^{10}$ In another study, mothers of children with ADHD presented less compassionate and affective parenting behavior than other parents. ${ }^{11}$ These parenting behaviors increased extrinsic symptoms, such as aggression, which leads to difficulties in parent-child interactions. ${ }^{12-14}$ Moreover, poor interaction between parents and children can further increase parental stress, leading to inadequate parenting behaviors and intensifying children's problematic behaviors, creating a vicious circle. ${ }^{15-18}$ These studies emphasize that parenting stress is an important factor in children's emotional development.

Among many parental stress evaluation tools used in Korea, the Parental Stress Scale (PSS) is designed to measure the level of stress experienced while raising children. ${ }^{8}$ This tool focuses solely on parental stress, unlike the parenting stress index (PSI), ${ }^{19}$ which does not separate marital and financial problems from parental stress, evaluating only specific areas of parental roles. ${ }^{8}$ Moreover, the PSS explains the parent-child relationship and measures how parents feel about the relationship; these aspects are not explored in the PSI. ${ }^{19}$

The PSS has been standardized and offered in Spanish, ${ }^{20}$ Portuguese, ${ }^{21}$ Chinese, ${ }^{22}$ and Danish. ${ }^{23}$ Notably, the PSS is frequently used to assess stress in parents of children with various diseases. Studies on stress in parents of children with chronic diseases have shown that parents suffer from high anxiety and depression and that their family functioning is low. ${ }^{24}$ One study compared the stress level of parents with typically developmental children versus parents of children with ADHD. ${ }^{25}$ The researchers found that parents of children with ADHD had higher stress levels. Also, parents of children with the combined type of ADHD and the inattentive type of ADHD had the highest and lowest stress level, respectively. ${ }^{25}$ When parents of children with cerebral palsy completed the PSS tests, the results showed that the severity of the disability did not affect parenting stress level. ${ }^{26}$ Another study reported that the PSS is a more suitable stress measure for parents of children with problematic behaviors than those with typical behavior. ${ }^{27}$ That same study shows that the PSS is more suitable for a clinical population than a typically developmental one. However, the PSS can be a useful tool for various purposes in clinical practice.

Standardizing an index for stress in the parenting role of typically developmental children has been performed in several studies. ${ }^{28,29}$ However, the stress scales and standardization for parents of children with ADHD are insufficient. Therefore, this study aimed to adapt and standardize the PSS for parents of children with ADHD in South Korea and assess its reliability and validity.

\section{METHODS}

\section{Data}

We retrospectively reviewed data from 174 parents (90 mothers, 84 fathers) whose children were diagnosed with $\mathrm{ADHD}$ after visiting the mental health department at a large hospital in Seoul for the first time between February 2018 and December 2019. These included parents of children diagnosed with ADHD, based on the DSM-5 diagnostic criteria, by a child and adolescent psychiatrist. Sociodemographic information such as age, level of education, and economic status of the parents was collected using a survey. The parents also completed the Korean version of the Adult Self Report (KASR), the Korean ADHD Rating Scales (K-ARS), the Patient Health Questionnaire-9 (PHQ-9), the State-Trait Anxiety Inventory (STAI), the PSS, and the Global Assessment of Recent Stress Scale (GARSS). Fourteen parents ( 8 mothers, 6 fathers) did not complete the surveys and were excluded. Therefore, data from 160 parents ( 82 mothers, 78 fathers) of 90 children and adolescents with ADHD were included in our final analysis. This sample size is $5-10$ times greater than the minimal number of items required to verify validity. ${ }^{30}$ The collected data were analyzed using SPSS 25.0 and AMOS 25.0 (IBM Corp., Armonk, NY, USA). This study was approved by the Institutional Review Board of Soonchunhyang University Seoul Hospital (2019-11-001).

\section{Questionnaires completed by the parents}

\section{Korean version of the Adult Self Report (K-ASR)}

The K-ASR is an evaluation tool that assesses emotional and behavioral problems in adults, adaptation status, and substance use such as alcohol and cigarettes. ${ }^{31}$ Its adaptation scale assesses relationships with friends, spouses/lovers, family, education, economic status, and jobs. In a study assessing the validity of K-ASR, Cronbach's alpha and convergent validity were $0.53-0.96$ and $0.75-0.94$, respectively, showing high reliability. ${ }^{32}$ In our study, demographic sub-items from the K-ASR tool, such as gender, age, level of education, and economic status, were collected.

\section{Korean ADHD Rating Scales (K-ARS)}

The K-ARS is a behavioral assessment scale developed to assess ADHD symptoms in school-aged children. ${ }^{32}$ It consists of 18 items in total, which are evaluated on a 4-point scale. "Not at all," "sometimes," "often," and "very often" are given a score of 1,2,3, and 4, respectively. Odd-numbered items assess carelessness, and even-numbered items evaluate hyperactivity and impulsivity. If more than five items are given a score of 3 or 4 , ADHD is suspected. So et al..$^{33}$ assessed the validity 
of the scale and found that Cronbach's alpha was $0.77-0.89$.

\section{Patient Health Questionnaire-9 (PHQ-9)}

PHQ-9 is a self-reported test that screens for and evaluates depression. ${ }^{34}$ It consists of nine items in total evaluated on a 4-point scale, where "not at all," "several days," "more than 3 days", and "almost every day" are given a score of $0,1,2$, and 3 , respectively. A total score of 0-4, 5-9, 10-19, and 20-27 indicate no depression, mild depression, moderate depression, and severe depression, respectively. In this study, the Korean version of the PHQ- 9 scale modified by An et al..$^{35}$ was used. The Cronbach's alpha and test-retest reliability were satisfactory, with scores of 0.95 and 0.91 , respectively.

\section{State-Trait Anxiety Inventory (STAI)}

The STAI is a self-reported test for adults, developed by Spielberger, consisting of 40 items with 20 items each on state anxiety and trait anxiety. ${ }^{36}$ Each item is assigned a score of 1 , 2,3 , and 4, indicating "not at all," "sometimes," "often," and "almost always," respectively. Items 1, 6, 7, 10, 13, 16, and 19 assess trait anxiety, while items 1, 2, 5, 8, 10, 11, 15, 16, 19, and 20 assess state anxiety with a reversed scoring system. A higher score indicates a higher level of anxiety. In the study by Hahn et al., ${ }^{37}$ Cronbach's alpha for state anxiety and trait anxiety were 0.89 and 0.93 , respectively.

\section{Parental Stress Scale (PSS)}

The PSS is a tool that measures the perception of stress related to parenting. ${ }^{8}$ It consists of 18 items with 10 and 8 items measuring stress and satisfaction with parental roles, respectively. The items are evaluated on a 5 -point scale, in which a score of 1, 2, 3, 4, and 5 indicate, respectively, "strongly disagree," "disagree," "neutral," "agree," and "strongly agree." The items for satisfaction with parenting (items 1, 2, 5, 6, 7, 8, 17, 18) are reverse scored, and the total score of the 18 items are combined. The total score ranges from 18 to 90 , with higher scores indicating higher stress in parenting. In a study that standardized this tool, Cronbach's alpha was 0.83 , and testretest reliability at a six-week interval was $0.81{ }^{8}$

\section{A Global Assessment of Recent Stress Scale (GARSS)}

The GARSS was developed by Linn ${ }^{38}$ The GARSS evaluates the level of perceived stress in the past week to assess the level of subjective stress experienced by the individual. The GARSS consists of eight items on work, job, school life, interpersonal relationships, changes in relationships, disease and injuries, financial problems, unusual happenings, changes in daily life, and overall perception of stress. Each item is evaluated on a 10-point scale from 0 (no stress) to 9 (extreme severe stress). The highest possible total score is 72 , with a high- er score indicating a higher level of stress. In the study by $\mathrm{Linn}^{38}$ the test-retest correlation coefficient of GARSS ranged from $r=0.69$ to $r=0.92 .{ }^{39}$ However, in a study conducted in Korea, test-retest reliability for GARSS was significantly high from 0.85-0.95, and Cronbach's alpha was $0.86(\mathrm{p}<0.05)$, which was also significantly high. ${ }^{40}$ We use the Korean version of the GARSS, translated by Koh and Park. ${ }^{39}$

\section{Statistical analysis}

\section{Face validity verification}

Approval for the use of the PSS was obtained from Berry and Jones, ${ }^{8}$ the original developers. The adapted tool by Kim et al. ${ }^{40}$ was reviewed by two specialists in mental health medicine with mutual independence to assess whether any significant modifications to the original tool and adapted content were necessary. The tool did not require any significant modifications for this study. ${ }^{40}$

\section{Construct validity and reliability}

We perform exploratory factor analysis (EFA) to assess the data on the inherent characteristics and family structure of parents of children with ADHD. Additionally, confirmatory factor analysis (CFA) was conducted to evaluate convergent validity, discriminant validity, and final model fit to verify the final items' suitability. The PHQ-9, STAI, and GARSS were used to verify concurrent validity. ${ }^{36,38}$ We used Cronbach's alpha to verify the reliability of the Korean version of the PSS for parents of children with ADHD.

\section{RESULTS}

\section{Demographic and clinical characteristics}

The general characteristics of the parents are presented in Table 1. There were more mothers than fathers in our sample, with the mean age of all parents at 43.36 years $( \pm 5.63)$. The average PSS score indicated a mid-level score (range: 0-90) for parenting stress; the average PHQ-9 score showed no depression; the average GARSS score also showed a mid-level (range: $0-80$ ) of overall stress. The average STAI scores showed relatively higher levels (range: $0-80$ ) of state and trait anxiety.

\section{Clinical characteristics of children}

Table 2 shows the general characteristics of the children. There were twice as many boys as girls; the mean age for all children was 11.28 ( \pm 3.70$)$. The mean K-ARS score also implies that the children's behavior had been labeled "often" (a score of 3 ) on at least five items on the ADHD test. 
Table 1. Clinical characteristics of parents of children with ADHD $(\mathrm{N}=160)$

\begin{tabular}{lc}
\hline \multicolumn{1}{c}{ Variable } & Value \\
\hline Sex & $78(48.80)$ \\
Male & $82(51.20)$ \\
Female & $43.36 \pm 5.63$ \\
Age & \\
Educational level & $110(68.80)$ \\
University graduate or higher & $46(28.70)$ \\
High school graduate & $4(2.50)$ \\
Middle school graduate or lower & \\
Economic status & $31(19.40)$ \\
High & $118(73.70)$ \\
Moderate & $11(6.90)$ \\
Low & $44.05 \pm 11.00$ \\
PSS & $3.99 \pm 3.82$ \\
PHQ-9 & $27.76 \pm 8.63$ \\
GARSS & $39.72 \pm 11.51$ \\
State anxiety & $37.75 \pm 9.94$ \\
Trait anxiety & \\
\hline Data arepresented & \\
\hline
\end{tabular}

Data are presented as mean \pm standard deviation or N (\%). PSS, Parental Stress Scale; PHQ-9, Patient Health Questionnaire-9; GARSS, Global Assessment of Recent Stress Scale

\section{Analysis of tool items}

We measured the correlation between the 18 items on the questionnaire, and the items "I will do everything necessary for my child $(\times 2)$," "Caring for my child(ren) sometimes requires more energy and time than usual $(\times 3)$," "I am sometimes worried if I am doing enough for my child(ren) $(\times 4)$," and "I feel close to my child(ren) $(\times 5)$," were excluded, as their correlation values were 0.4 or less. Cronbach's alpha of all items, excluding these four, was 0.88 , which confirmed a high correlation. Thus, 14 items were selected for the model (Table 3 ).

\section{Validity analysis}

\section{Analysis of exploratory factors}

The Kaiser-Meyer-Olkin (KMO) test was conducted to de-

Table 2. Clinical characteristics of children

\begin{tabular}{lc}
\hline \multicolumn{1}{c}{ Variable } & Value \\
\hline Sex & $60(66.67)$ \\
Boys & $30(33.33)$ \\
Girls & $11.28 \pm 3.70$ \\
Age & $90(100), 19.99 \pm 10.67$ \\
K-ARS & \\
\hline Data are presented as mean \pm standard deviation or N (\%). K-ARS, \\
Korean ADHD Rating Scales
\end{tabular}

Table 3. Cronbach's alpha for each item

\begin{tabular}{lcc}
\hline \multicolumn{1}{c}{ Item } & $\begin{array}{c}\text { Item total } \\
\text { correlation }\end{array}$ & $\begin{array}{c}\text { Cronbach's alpha } \\
\text { if item deleted }\end{array}$ \\
\hline$\times 1$ I am happy with my role as a parent & 0.61 & 0.88 \\
$\times 2$ (D) I will do everything necessary for my child & 0.23 & 0.29 \\
$\times 3$ (D) Caring for my child(ren) sometimes requires more energy and time than usual & 0.28 & 0.89 \\
$\times 4$ (D) I am sometimes worried if I am doing enough for my child(ren) & 0.40 & 0.89 \\
$\times 5$ (D) I feel close to my child(ren) & 0.58 & 0.89 \\
$\times 6$ I enjoy spending time with my child(ren) & 0.46 & 0.51 \\
$\times 7$ My child(ren) is (are) an important source of affection & 0.59 & 0.88 \\
$\times 8$ Having (a) child(ren) gives me a more clear and optimistic view of the future & 0.66 \\
$\times 9$ The main source of stress in my life is my child(ren) & 0.50 \\
$\times 10$ Having a child(ren) means that I have little time and flexibility in my life & 0.68 \\
$\times 11$ Having a child(ren) was an economic burden & 0.57 \\
$\times 12$ It is difficult to balance other responsibilities with my child(ren) & 0.88 \\
$\times 13$ Actions of my child often embarrass me or make me nervous & 0.60 \\
$\times 14$ If I could go back in time, I would not have children & 0.63 \\
$\times 15$ I am overwhelmed by my responsibility as a parent & 0.62 \\
$\times 16$ Having child(ren) has meant that I have limited choice and control over my life & 0.58 \\
$\times 17$ I am satisfied as a parent & 0.52 \\
$\times 18$ I know that my child(ren) are having fun &
\end{tabular}

$\mathrm{D}$, delete 
termine the suitability of the exploratory factor analysis on the 14 items of the PSS. The standard fit was 0.83 , which is higher than 0.60 , the level considered acceptable. Thus, exploratory factor analysis was considered suitable for this study. Moreover, the result of Bartlett's sphericity test was $\chi^{2}=955.67$ $(\mathrm{p}<0.001)$, rejecting the null hypothesis of the unit matrix. As a result, two factors were extracted from the 14 items (Table 4). Factors 1 and 2 had variances of 29.70 and 24.17 , respectively, with an explanatory power of $53.86 \%$ (Table 5 ). Therefore, factor analysis was judged to be appropriate, and factors 1 and 2 were categorized as "parental stress" and "parental satisfaction," respectively.

\section{Analysis of confirmatory factors}

Confirmatory factor analysis was conducted to verify the

Table 4. Exploratory factor analysis of PSS

\begin{tabular}{|c|c|c|}
\hline Items & $\begin{array}{c}\text { Factor } 1 \\
\text { (parental } \\
\text { role stress) }\end{array}$ & $\begin{array}{c}\text { Factor } 2 \\
\text { (parental role } \\
\text { satisfaction) }\end{array}$ \\
\hline$\times 10$ & 0.82 & \\
\hline$\times 16$ & 0.77 & \\
\hline$\times 12$ & 0.74 & \\
\hline$\times 15$ & 0.74 & \\
\hline$\times 9$ & 0.69 & \\
\hline$\times 13$ & 0.63 & \\
\hline$\times 11$ & 0.55 & \\
\hline$\times 14$ & 0.53 & \\
\hline$\times 6$ & & 0.79 \\
\hline$\times 18$ & & 0.76 \\
\hline$\times 1$ & & 0.70 \\
\hline$\times 17$ & & 0.69 \\
\hline$\times 7$ & & 0.66 \\
\hline$\times 8$ & & 0.53 \\
\hline Eigen value & 5.95 & 1.59 \\
\hline$\%$ of variance & 42.50 & 11.37 \\
\hline Cumulative \% & 53.87 & \\
\hline Bartlett's sphericity test $\chi^{2}$ & 955.67 & \\
\hline
\end{tabular}

$\mathrm{p}<0.001$. PSS, Parental Stress Scale
14 items of the two factors in the Korean version of the PSS for parents of children with ADHD. Factor analysis showed the model fit and, in general, $\chi^{2} / \mathrm{df}=3$ or less, goodness-of-fit index (GFI), adjusted goodness-of-fit index (AGFI), comparative fit index (CFI), and Tucker-Lewis Index (TFI) $=0.9$ or more, root mean residual square $(\mathrm{RMR})=0.05$ or less, and root mean square error approximation $($ RMSEA $)=0.08$ or less are considered appropriate. ${ }^{41}$ In the first model, the overall goodness-of-fit indices, except for CFI, were not satisfactory, suggesting that the fit was poor. In the second model, items 7, 8, and 11 , with a relatively low standardization coefficient of .6 or less, were deleted from the first model (Figure 1). Once these items were deleted, the goodness of fit of the second model was $\chi^{2} / \mathrm{df}=2.69(\mathrm{RMR}=0.07, \mathrm{GFI}=0.90, \mathrm{AGFI}=0.85$, $\mathrm{CFI}=0.94$, TLI $=0.92$, and RMSEA $=0.08$ ), which was satisfactory. Thus, the second model was selected as the final model for this study (Table 6).

\section{Convergent validity}

Convergence validity was assessed using the final model. The critical ratio (CR) for F1 (parental stress) and F2 (parental satisfaction) was greater than 2 for both, and the standardization coefficient was at least 0.5 , which was statistically significant. Additionally, AVE and construct reliability were above 0.5 and 0.7 , respectively, indicating good convergent validity. Therefore, all acceptable criteria were satisfied (Table 7).

\section{Discriminant validity}

Discriminant validity tests, whether conceptually different constructs or measurements that are not supposed to be related, are actually unrelated. It is assessed by examining whether the value of $\sqrt{A V E}>\emptyset$ exceeds the correlation coefficient value $\sqrt{A V E}>\emptyset$ of $\sqrt{A V E}>\emptyset$ with other variables $\sqrt{A V E}>\emptyset^{42}$ The value of $\sqrt{A V E}>\emptyset$ exceeded all correlation values $\sqrt{A V E}>\emptyset$ of $\sqrt{A V E}>\varnothing$ between concepts. Thus, the tool satisfied the standards of discriminant validity criteria (Table 8).

\section{Concurrent validity}

The concurrent validity of the PSS was assessed by examining the correlation through PHQ-9, STAI, and GARSS. The

Table 5. Principal component analysis

\begin{tabular}{|c|c|c|c|c|c|c|c|c|c|}
\hline & \multicolumn{3}{|c|}{ Initial eigenvalue } & \multicolumn{3}{|c|}{ Extraction sums of squared loadings } & \multicolumn{3}{|c|}{ Rotation sums of squared loadings } \\
\hline & Total & $\%$ Distributed & Cumulative \% & Total & $\%$ Distributed & Cumulative \% & Total & $\%$ Distributed & Cumulative $\%$ \\
\hline 1 & 5.95 & 42.50 & 42.50 & 5.95 & 42.50 & 42.50 & 4.16 & 29.70 & 29.70 \\
\hline 2 & 1.59 & 11.37 & 53.87 & 1.59 & 11.37 & 53.87 & 3.38 & 24.17 & 53.87 \\
\hline 3 & 0.96 & 6.83 & 60.69 & & & & & & \\
\hline 4 & 0.86 & 6.15 & 66.84 & & & & & & \\
\hline
\end{tabular}

Component: each item 


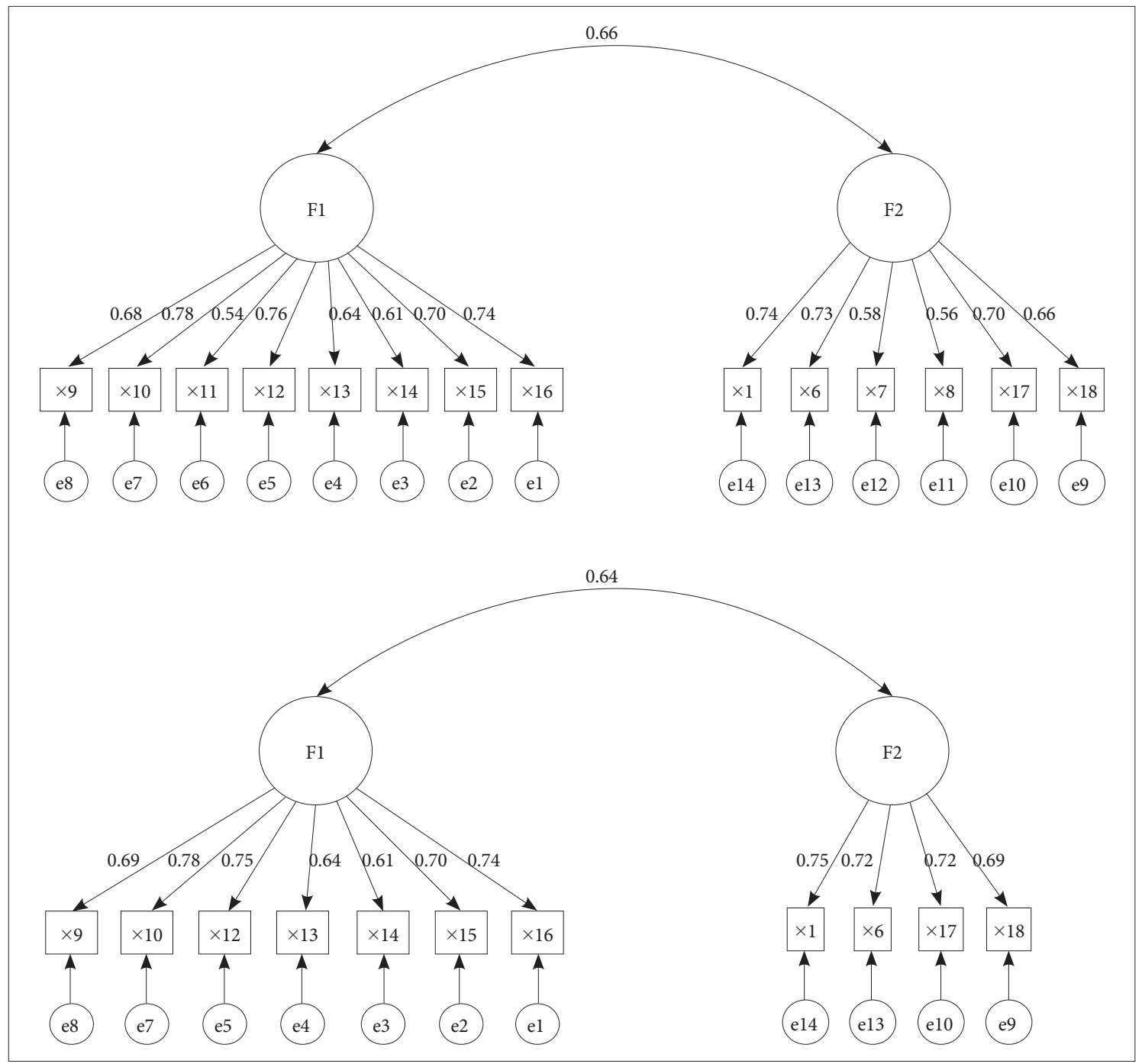

Figure 1. The final model according to the Parental Stress Scale sub-factors.

Table 6. PSS model goodness of fit

\begin{tabular}{lccccccc}
\hline Model fit & $\chi^{2} / \mathrm{df}$ & GFI & AGFI & RMR & CFI & TLI & RMSEA \\
\hline Model 1 & 2.07 & 0.88 & 0.83 & 0.07 & 0.91 & 0.89 & 0.08 \\
Model 2 & 2.09 & 0.90 & 0.85 & 0.07 & 0.94 & 0.92 & 0.08
\end{tabular}

GFI, Goodness of Fit Index; AGFI, Adjusted Goodness of Fit Index; RMR, Root Mean Residual Square; CFI, Comparative Fit Index; TLI, Tucker-Lewis Index; RMSEA, Root Mean Square Error Approximation

PSS was significantly correlated with PHQ-9, STAI, and GARSS, with p values of $0.46,0.56$, and 0.43 , respectively (Table 9 ).

\section{Reliability verification}

Cronbach's alpha, measured to verify the reliability of the 14 items, was 0.88 . For the 11 items selected in the final model, Cronbach's alpha was 0.88 , which showed a high internal consistency above 0.80 . Cronbach's alpha was 0.87 and 0.81 , respectively, for the seven items of parental stress and the four of parental satisfaction.

\section{DISCUSSION}

The purpose of this study was to assess whether the PSS could be used for parents of children with ADHD by evaluating its validity and reliability since it was originally developed for parents of typically developmental children or children with other diseases. Content validity, construct validity, concurrent validity, and reliability of the final 11 items and the two sub-factors of "parental stress" and "parental satisfaction" of the PSS demonstrated that the PSS could be revised to consist of appropriate content to measure role stress in parents of children with ADHD (Supplementary Table 1 in the online-only Data Supplement).

When the factor structures of our tool were compared with 
Table 7. Convergent validity for each item

\begin{tabular}{|c|c|c|c|c|c|c|c|}
\hline & & $\begin{array}{c}\text { Non-standardized } \\
\text { coefficient }\end{array}$ & SE & CR & $\begin{array}{c}\text { Standardized } \\
\text { coefficient }\end{array}$ & AVE & Construct reliability \\
\hline$\times 16$ & $\leftarrow \quad \mathrm{F} 1$ & 1 & & & 0.74 & \multirow{7}{*}{0.50} & \multirow{7}{*}{0.87} \\
\hline$\times 15$ & $\leftarrow \quad F 1$ & 1.13 & 0.13 & 8.47 & 0.70 & & \\
\hline$\times 14$ & $\leftarrow \quad F 1$ & 0.79 & 0.11 & 7.32 & 0.61 & & \\
\hline$\times 13$ & $\leftarrow \mathrm{F} 1$ & 1.00 & 0.13 & 7.76 & 0.64 & & \\
\hline$\times 12$ & $\leftarrow \quad F 1$ & 1.04 & 0.12 & 9.07 & 0.75 & & \\
\hline$\times 10$ & $\leftarrow \quad \mathrm{F} 1$ & 1.14 & 0.12 & 9.52 & 0.78 & & \\
\hline$\times 9$ & $\leftarrow \quad \mathrm{F} 1$ & 1.13 & 0.13 & 8.38 & 0.69 & & \\
\hline$\times 18$ & $\leftarrow \quad \mathrm{F} 2$ & 1 & & & 0.69 & \multirow{4}{*}{0.52} & \multirow{4}{*}{0.81} \\
\hline$\times 17$ & $\leftarrow \quad$ F2 & 1.13 & 0.15 & 7.59 & 0.72 & & \\
\hline$\times 6$ & $\leftarrow \quad \mathrm{F} 2$ & 0.97 & 0.13 & 7.60 & 0.72 & & \\
\hline$\times 1$ & $\leftarrow \quad \mathrm{F} 2$ & 1.06 & 0.14 & 7.82 & 0.75 & & \\
\hline
\end{tabular}

SE, standard error; CR, construct reliability; AVE, average variance extracted

Table 8. Discriminant validity for each item

\begin{tabular}{|c|c|c|c|c|c|c|c|c|c|c|c|}
\hline & $\times 9$ & $\times 10$ & $\times 12$ & $\times 13$ & $\times 14$ & $\times 15$ & $\times 16$ & $\times 1$ & $\times 6$ & $\times 17$ & $\times 18$ \\
\hline$\times 9$ & 0.71 & & & & & & & & & & \\
\hline$\times 10$ & 0.61 & 0.71 & & & & & & & & & \\
\hline$\times 12$ & 0.51 & 0.57 & 0.71 & & & & & & & & \\
\hline$\times 13$ & 0.54 & 0.51 & 0.49 & 0.71 & & & & & & & \\
\hline$\times 14$ & 0.41 & 0.37 & 0.48 & 0.37 & 0.71 & & & & & & \\
\hline$\times 15$ & 0.49 & 0.56 & 0.46 & 0.38 & 0.48 & 0.71 & & & & & \\
\hline$\times 16$ & 0.38 & 0.63 & 0.59 & 0.43 & 0.46 & 0.57 & 0.71 & & & & \\
\hline$\times 1$ & 0.33 & 0.38 & 0.35 & 0.31 & 0.42 & 0.42 & 0.40 & 0.72 & & & \\
\hline$\times 6$ & 0.30 & 0.30 & 0.34 & 0.31 & 0.36 & 0.32 & 0.24 & 0.50 & 0.72 & & \\
\hline$\times 17$ & 0.26 & 0.31 & 0.39 & 0.33 & 0.42 & 0.33 & 0.39 & 0.57 & 0.48 & 0.72 & \\
\hline$\times 18$ & 0.33 & 0.20 & 0.35 & 0.34 & 0.34 & 0.22 & 0.20 & 0.48 & 0.59 & 0.47 & 0.72 \\
\hline
\end{tabular}

Diagonal matrix is $\sqrt{A V E}>\emptyset$. AVE, average variance extracted

those in the original version, we found several differences. In the original tool, factors related to parental satisfaction, parental stress, parenting compensation, and lack of control were included. However, only parental satisfaction and parental stress were assessed to be appropriate here. This is consistent with the findings in a study on the Spanish version of the PSS, ${ }^{20}$ where only two factors are assessed to be appropriate. Therefore, a PSS structure with two factors is thought to be effective.

As stated, in our study, the factor analysis reveals two subfactors. Factor 1 consisted of eight items on parental stress and had the highest explanatory power and the highest importance among the measurement tools tested in this study. Parental stress refers to the level of parenting difficulty or burden perceived by parents. ${ }^{43}$ As family structures and roles have changed recently, parenting responsibilities have increased, leading to greater parental stress. ${ }^{43,44}$ Factor 2, parental satisfaction, which had an explanatory power of $11.365 \%$, consist-
Table 9. Concurrent validity

\begin{tabular}{llccc}
\hline & PSS & PHQ-9 & State anxiety & GARSS \\
\hline PSS & 1.00 & $0.46^{*}$ & $0.56^{*}$ & $0.43^{*}$ \\
PHQ-9 & $0.46^{*}$ & 1.00 & $0.65^{*}$ & $0.58^{*}$ \\
State anxiety & $0.56^{*}$ & $0.65^{*}$ & 1.00 & $0.57^{*}$ \\
GARSS & $0.43^{*}$ & $0.58^{*}$ & $0.57^{*}$ & 1.00 \\
\hline
\end{tabular}

${ }^{*} \mathrm{p}<0.001$. PSS, Parental Stress Scale; PHQ-9, Patient Health Questionnaire-9; GARSS, Global Assessment of Recent Stress Scale

ed of six items. Parental satisfaction refers to the level of subjective satisfaction from parenting. ${ }^{45}$ As parental satisfaction improves, their affection toward and interest in children increase, which enhances children's abilities. Furthermore, tension and conflict with parents in daily life are reduced, and life satisfaction increases, creating a positive family environment. ${ }^{46}$ In other words, parental satisfaction is an important factor contributing to children's development and improving life 
satisfaction of the parents. ${ }^{47}$

As validity measures the accuracy of a measurement tool, we were able to apply various means of validating the accuracy of the K-PSS-ADHD tool for parents of children with ADHD; ${ }^{48}$ namely, we assessed convergent validity, discriminant validity, and concurrent validity. Convergent and discriminant validity were shown to measure the sub-domains for each item consistently. However, certain items, specifically item 7 "My child(ren) is an important source of affection," item 8 "having a child(ren) gives a more clear and optimistic view of the future," and item 11 "having a child(ren) is an economic burden," showed the risk of not distinguishing the relationship with other sub-areas; thus, these items were excluded. Finally, PHA-Q, STAI, and GARSS were used to assess concurrent validity, and were statistically significant at $0.43-0.56$. Parental stress and depression were positively correlated, as shown in previous studies. ${ }^{49}$ Parents felt frustrated or depressed when they believed that they were not carrying out their parental role. ${ }^{50}$ The parenting stress variable predicts depression, ${ }^{51}$ and depression in mothers relates to ADHD in children. Based on this evidence, there is a likelihood of incidence of depression in mothers of children suspected of having ADHD. ${ }^{52}$ Parental stress was positively correlated with STAI and GARSS, which was consistent with the study's findings on the Spanish version of the PSS. ${ }^{20}$ In previous studies, mothers of children with disabilities showed a higher level of stress compared with mothers of typically developmental children, and parenting stress and anxiety were positively related. ${ }^{53}$ As such, correlation in this study satisfied the criterion that a correlation of $0.4-0.8$ is appropriate, verifying the validity of this study. ${ }^{54}$

Ultimately, we found that the K-PSS-ADHD can be a reliable tool for assessing parental stress. The reliability of the sub-factors and the entire tool was remarkably high at $0.81^{-}$ 0.88 , which was appropriate when comparing this with the Cronbach's alpha of 0.83 at the time of development ${ }^{8}$ and Cronbach's alpha of 0.89 in the Hongkong version. ${ }^{55}$ Thus, we can see that this tool's items have high reliability and explanatory powers.

The main limitation of our study is the difficulty in generalizing the sample size, which was limited since we only analyzed parent data from a single institution. Therefore, more specific data need to be collected in subsequent studies from multiple institutions. Second, the children in our study had low K-ARS scores, indicating mild behavioral patterns. Thus, a larger study could include a broader pool of children. Moreover, sub-types of ADHD were not considered, which could lead to insufficient uniformity in the sample. In future studies, changes in parental stress scores should be analyzed according to subtypes of ADHD.

In conclusion, this study attempted to standardize a PSS tool

for South Korea that captures sub-factors of stress for parents of children with ADHD and verify its validity and reliability. Moreover, as we were able to verify its content validity, construct validity, concurrent validity, and internal consistency, we believe that the K-PSS-ADHD can be effective in evaluating stress in parents of children with ADHD. It proves to be a reliable and valid basis for measuring stress in parents of children with ADHD. Therefore, we hope these findings can be the basis for future studies on stress in parents of children with ADHD in South Korea.

\section{Supplementary Materials}

The online-only Data Supplement is available with this article at https://doi.org/10.30773/pi.2021.0116.

\section{Availability of Data and Material}

The datasets generated or analyzed during the study are available from the corresponding author on reasonable request.

\section{Conflicts of Interest}

The authors have no potential conflicts of interest to disclose.

\section{Unblinded Statements}

Methods: We retrospectively reviewed data from 174 parents (90 mothers, 84 fathers) whose children were diagnosed with ADHD after visiting the Department of Mental Health at Soonchunhyang University Seoul Hospital for the first time between February 2018 and December 2019.

\section{Author Contributions}

Conceptualization: Yeon Jung Lee. Data curation: Seo Young Park. Formal analysis: Yeon Jung Lee. Funding acquisition: Yeon Jung Lee. Investigation: Seo Young Park, Mi Young Jeong, Yun Sung Lee, Jeong Eun Shin. Methodology: Yeon Jung Lee. Project administration: Seo Young Park, Yeon Jung Lee. Resources: Yeon Jung Lee. Software: Jung Ho Kim, Yeon Jung Lee. Supervision: Jung Ho Kim, Yeon Jung Lee. Validation: Seo Young Park, Yeon Jung Lee. Visualization: Jung Ho Kim. Writing—original draft: Seo Young Park. Writing — review \& editing: Seo Young Park, Jung Ho Kim, Yeon Jung Lee.

\section{ORCID iDs}

Seo Young Park https://orcid.org/0000-0002-5033-8689 Jung Ho Kim Mi Young Jeong Yun Sung Lee Jeong Eun Shin Yeon Jung Lee

https://orcid.org/0000-0003-2763-7186 https://orcid.org/0000-0002-2409-8060 https://orcid.org/0000-0002-5110-7225 https://orcid.org/0000-0002-3827-4440 https://orcid.org/0000-0001-8953-5893

\section{Funding Statement}

This work was supported by a National Research Foundation of Korea (NRF) grant funded by the Korea government (MSIT) (No. 2017R1C1B507 4462) and the Soonchunhyang University Research Fund.

\section{REFERENCES}

1. American Psychiatric Association. Diagnostic and Statistical Manual of Mental Disorders (DSM-5). Washington, DC: American Psychiatric Association; 2013.

2. An NY, Lee JY, Cho SM, Chung YK, Shin YM. Difficulty in facial emotion recognition in children with ADHD. J Korean Acad Child Adolesc Psychiatry 2013;24:83-89. 
3. Schachar R, Taylor E, Wieselberg M, Thorley G, Rutter M. Changes in family function and relationships in children who respond to methylphenidate. J Am Acad Child Adolesc Psychiatry 1987;26:728-732.

4. Barkley R. Primary Symptoms and Conceptualization in Attention Deficit Hyperactivity Disorder: A Handbook for Diagnosis and Treatment. New York: Guilford Press; 1990.

5. Cho SC. Concept and biological study of attention deficit hyperactivity disorder. J Korean Acad Child Adolesc Psychiatry 1990;1:5-26.

6. Barkley RA, Karlsson J, Pollard S, Murphy JV. Developmental changes in the mother-child interactions of hyperactive boys: effects of two dose levels of Ritalin. J Child Psychol Psychiatry 1985;26:705-715.

7. Mash EJ, Johnston C. Parental perceptions of child behavior problems, parenting self-esteem, and mothers' reported stress in younger and older hyperactive and normal children. J Consult Clin Psychol 1983;51:8699.

8. Berry JO, Jones WH. The parental stress scale: initial psychometric evidence. J Soc Personal Relatsh 1995;12:463-472.

9. Graziano PA, McNamara JP, Geffken GR, Reid A. Severity of children's ADHD symptoms and parenting stress: a multiple mediation model of self-regulation. J Abnorm Child Psychol 2011;39:1073-1083.

10. Barber BK. Parental psychological control: revisiting a neglected construct. Child Dev 1996;67:3296-3319.

11. Kim SY, Hwang JW, Kim BN, Cho SC, Shin MS. Parents' rearing attitude of children with attention-deficit hyperactivity disorder and depressive disorder. J Korean Acad Child Adolesc Psychiatry 2008;19:175181

12. Hart CH, Nelson DA, Robinson CC, Olsen SF, McNeilly-Choque MK. Overt and relational aggression in Russian nursery-school-age children: parenting style and marital linkages. Dev Psychol 1998;34:687-697.

13. McLaughlin DP, Harrison CA. Parenting practices of mothers of children with ADHD: the role of maternal and child factors. Child Adolesc Ment Health 2006;11:82-88.

14. Modesto-Lowe V, Danforth JS, Brooks D. ADHD: does parenting style matter? Clin Ped 2008;47:865-872.

15. Seipp CM, Johnston C. Mother-son interactions in families of boys with attention-deficit/hyperactivity disorder with and without oppositional behavior. J Abnorm Child Psychol 2005;33:87-98.

16. Spratt EG, Saylor CF, Macias MM. Assessing parenting stress in multiple samples of children with special needs (CSN). Fam Syst Health 2007; 25:435-449.

17. Woodward L, Taylor E, Dowdney L. The parenting and family functioning of children with hyperactivity. J Child Psychol Psychiatry 1998;39: 161-169.

18. Bae JY. Effects of clinical art therapy on improving concentration and aggression of ADHD prone children. Korean Acad Clin Art Ther 2011; 6:105-121.

19. Ochoa B, Repáraz C, Lorente AP. Validación de la escala cilc, de locus de control, en una muestra española de padres de niños hospitalizados. Psicothema 1997;9:89-103.

20. Oronoz Artola B, Alonso Arbiol I, Balluerka Lasa MN. A Spanish adaptation of the parental stress scale. Psicothema 2007;19:687-692.

21. Brito AD, Faro A. Differences by gender, adaptation and validation of the Parental Stress Scale. Avaliação Psicológica 2017;16:38-47.

22. Leung C, Tsang SK. The Chinese parental stress scale: psychometric evidence using Rasch modeling on clinical and nonclinical samples. J Pers Assess 2010;92:26-34.

23. Pontoppidan M, Nielsen T, Kristensen IH. Psychometric properties of the Danish Parental Stress Scale: rasch analysis in a sample of mothers with infants. PLoS One 2018;13:e0205662.

24. Zelman JJ, Ferro MA. The parental stress scale: psychometric properties in families of children with chronic health conditions. Fam Relat 2018;67:240-252.

25. Sethi S, Gandhi R, Anand V. Study of level of stress in the parents of children with Attention-Deficit/Hyperactivity Disorder. J Indian Assoc Child Adolesc Ment Health 2012;8:25-37.
26. Kriti K, Pradhan A, Tufel S. Severity of cerebral palsy and its impact on level of stress in the caregivers: a correlational study. Indian J Occup Ther 2019;51:21-25.

27. Nielsen T, Pontoppidan M, Rayce SB. The Parental Stress Scale revisited: rasch-based construct validity for Danish parents of children 2-18 years old with and without behavioral problems. Health Qual Life Outcomes 2020;18:1-6.

28. Jung KM, Lee SI, Lee CS. Standardization study for the Korean Version of Parenting Stress Index Fourth Edition (K-PSI-4). Korean J Psychol Gen 2019;38:247-273.

29. Jung KM, Lee CS, Lee SI. Standardization study for the Korean Version of Stress Index for Parents of Adolescents (K-SIPA). Korean J Psychol Gen 2019;38:419-441.

30. Bryant FB, Yarnold PR. Principal-Components Analysis and Exploratory and Confirmatory Factor Analysis. In: Grimm LG, Yarnold PR, Editors. Reading and Understanding Multivariate Statistics. Washington, DC: American Psychological Association, 1995, p.99-136.

31. Kim MY, Kim YA, Lee J, Kim HJ, Oh KJ. A validity study on the Korean version of the adult self report. Korean J Clin Psychol 2014;33:615-632.

32. Murphy K, Barkley RA. Preliminary normative data on DSM-IV criteria for adults. ADHD Report 1995;3:6-7.

33. So YK, Noh JS, Kim YS, Ko SG, Koh YJ. The reliability and validity of Korean Parent and Teacher ADHD Rating Scale. J Korean Neuropsychiatr Assoc 2002;41:283-289.

34. Kroenke K, Spitzer RL, Williams JB. The PHQ-9: validity of a brief depression severity measure. J Gen Intern Med 2001;16:606-613.

35. An JY, Seo ER, Lim KH, Shin JH, Kim JB. Standardization of the Korean version of screening tool for depression (Patient Health Questionnaire-9, PHQ-9). J Korean Soc Biol Ther Psychiatry 2013;19:47-56.

36. Spielberger CD. Manual for the State-Trait Anxiety Inventory (SelfEvaluation Questionnaire). Palo Alto: Consulting Psychologists Press; 1970.

37. Hahn DW, Lee CH, Tak JG. Standardization of Spielberger State-Trait Anxiety Test. In Korea Institute of Psychology Proceedings of the 93' General Conference, 1993, p.505-512.

38. Linn MW. A global assessment of recent stress (GARS) scale. Int J Psychiatry Med 1986;15:47-59.

39. Koh KB, Park JK. Validity and reliability of the Korean version of the global assessment of recent stress scale. Korean J Psychosomatic Med 2000;8:201-211.

40. Kim YS, Jeon YJ, Hak JS, Kim JS. Family Assessment Handbook. In: Kim YS, Jeon YJ, Hak JS, Kim JS, Editors. Family Evaluation and Family Counseling. Seoul: Hakji-sa; 2003, p.28-33.

41. Woo JP. Concept and understanding of Structural Equation Model. Seoul: Hannarae; 2012.

42. Fornell C, Larcker DF. Structural Equation Models with Unobservable Variables and Measurement Error: Algebra and Statistics. Los Angeles, CA: Sage Publications; 1981

43. Kim MY, Park DY. Parenting stress, depression and verbal abuse of infant's mothers. Child Health Nurs Res 2009;15:375-382.

44. Kim MW, Kang MJ. The effects of double-income couples' gender role attitudes and recognition of social support on parenting stress. J Korean Home Econ Assoc 2011;49:25-35.

45. Han MS, Lee YJ. The appearance satisfaction according to parents' appearance-related parenting style and undergraduate children's self-esteem. J Korean Home Econ Educ Assoc 2007;19:247-256.

46. Guidubaldi J, Cleminshaw HK. The development of the Cleminshaw-Guidubaldi parent satisfaction scale. J Clin Child Psychol 1985;14: 293-298.

47. Park HS, Koo HY. Effects of the Core Competency Support Program in parenting role on sense of competence in parenting, parent-child communication, and parental role satisfaction in parents of adolescents. J Korean Acad Psychiatric Ment Health Nurs 2010;19:411-419.

48. Rothstein JM. Primer on Measurement: An Introductory Guide to Measurement Issues, Featuring the American Physical Therapy Asso- 
ciation's Standards for Tests and Measurements in Physical Therapy Practice. Alexandria, VA: Am Physical Therapy Assn; 1993.

49. Weitlauf AS, Vehorn AC, Taylor JL, Warren ZE. Relationship satisfaction, parenting stress, and depression in mothers of children with autism. Autism 2014;18:194-198.

50. Anthony LG, Anthony BJ, Glanville DN, Naiman DQ, Waanders C, Shaffer $\mathrm{S}$. The relationships between parenting stress, parenting behaviour and preschoolers' social competence and behaviour problems in the classroom. Infant and Child Development. Int J Res Pract 2005;14:133154.

51. Lee ON, Park KA. The mediating effect of social support on the relationship between parental stress and depression among parents of children with a disability. J Korean Entertain Indust Assoc 2020;14:411419 .
52. Cheung K, Aberdeen K, Ward MA, Theule J. Maternal depression in families of children with ADHD: a meta-analysis. J Child Fam Stud 2018;27:1015-1028.

53. Seo W, Kim D. The effects of the maternal anxiety, parenting attitude \& psychological well-being on parenting stress: a comparative study between mothers who have children with and without disabilities. Korean J Dev Psychol 2013;26:121-136.

54. Lee EO, Lim NY, Park HA, Lee IS, Kim JI, Bae JY, et al. Nursing Research and Statistical Analysis. In: Lee EO, Lim NY, Park HA, Lee IS, Kim JI, Bae JY, Lee SM, Editors. Statistics. Paju: Soomoonsa; 2009, p.340-347.

55. Cheung SK. Psychometric properties of the Chinese version of the Parental Stress Scale. Psychologia 2000;43:253-261. 
Supplementary Table 1. Final parental stress scale for Korean parents of children with ADHD

\begin{tabular}{|c|c|c|c|c|c|c|}
\hline Q. no. & Items & Strongly disagree & Disagree & Neutral & Agree & Strongly agree \\
\hline 1 & *I am happy with my role as a parent. & 1 & 2 & 3 & 4 & 5 \\
\hline 2 & *I enjoy spending time with my child(ren). & 1 & 2 & 3 & 4 & 5 \\
\hline 3 & The main source of stress in my life is my child(ren). & 1 & 2 & 3 & 4 & 5 \\
\hline 4 & Having a child(ren) means that I have little time and flexibility in my life. & 1 & 2 & 3 & 4 & 5 \\
\hline 5 & It is difficult to balance other responsibilities with that for my child(ren). & 1 & 2 & 3 & 4 & 5 \\
\hline 6 & Actions of my child(ren) often embarrass me or make me nervous. & 1 & 2 & 3 & 4 & 5 \\
\hline 7 & If I can go back in time, I will not have children. & 1 & 2 & 3 & 4 & 5 \\
\hline 8 & I am overwhelmed by my responsibility as a parent. & 1 & 2 & 3 & 4 & 5 \\
\hline 9 & Having a child(ren) has meant that I have limited choice and control over my life. & 1 & 2 & 3 & 4 & 5 \\
\hline 10 & *I am satisfied as a parent. & 1 & 2 & 3 & 4 & 5 \\
\hline 11 & *I know that my child(ren) are having fun. & 1 & 2 & 3 & 4 & 5 \\
\hline
\end{tabular}

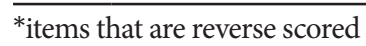

